\title{
Role of heme oxygenase- 1 in protection of the kidney after hemorrhagic shock
}

\author{
YUTAKA ARIMORI, TORU TAKAHASHI, HIROYUKI NISHIE, KAZUYOSHI INOUE, \\ HIROKO SHIMIZU, EMIKO OMORI, SUSUMU KAWANISHI, YUICHIRO TODA, \\ HIROSHI MORIMATSU and KIYOSHI MORITA
}

\begin{abstract}
Department of Anesthesiology and Resuscitology, Okayama University Medical School, 2-5-1 Shikata-cho, Kita Ward, Okayama 700-8558, Japan
\end{abstract}

Received January 25, 2010; Accepted March 16, 2010

DOI: 10.3892/ijmm_00000430

\begin{abstract}
Hemorrhagic shock followed by resuscitation (HSR) causes oxidative stress, which results in multiple organ damage. The kidney is one of the target organs of HSR-mediated oxidative tissue injury. Heme oxygenase (HO)-1, the rate-limiting enzyme in heme catabolism, is induced by oxidative stress; it protects against oxidative tissue injuries. The aim of the present study was to examine the role of renal HO-1 induction after HSR. Rats were subjected to hemorrhagic shock to achieve a mean arterial pressure of $30 \mathrm{mmHg}$ for $60 \mathrm{~min}$, followed by resuscitation with the shed blood. HSR resulted in a significant increase in functional HO-1 protein in the tubular epithelial cells of the kidney, whereas HSR resulted in only a slight increase in gene expression of tumor necrosis factor (TNF)- $\alpha$ and inducible nitric oxide synthase (iNOS), and in protein expression of activated caspase-3 solely in renal cells where HO-1 expression was absent. HSR also resulted in a significant increase in Bcl-2 gene expression. Pretreatment of HSR animals with tinmesoporphyrin $(0.5 \mu \mathrm{mol} / \mathrm{kg})$, a specific competitive inhibitor of $\mathrm{HO}$ activity, resulted in a significant decrease in $\mathrm{HO}$ activity and exacerbated tissue inflammation and apoptotic cell death as judged by the marked increase in expression of TNF- $\alpha$ and iNOS, and in activated caspase-3-positive cells, and the significant reduction in $\mathrm{Bcl}-2$ expression, respectively. These findings indicate that $\mathrm{HO}-1$ induction is an adaptive response to HSR-induced oxidative stress and is essential for protecting tubular epithelial cells from oxidative damage through its anti-inflammatory and anti-apoptotic properties.
\end{abstract}

\section{Introduction}

Heme oxygenase (HO)-1 is the rate-limiting enzyme in heme catabolism; it is also known as a heat shock protein (HSP 32)

Correspondence to: Dr Toru Takahashi, Department of Anesthesiology and Resuscitology, Okayama University Medical School, 2-5-1 Shikata-cho, Kita Ward, Okayama 700-8558, Japan E-mail: takatoru@cc.okayama-u.ac.jp

Key words: apoptosis, inflammation, oxidative stress, resuscitation and a stress-inducible protein $(1,2)$. HO-1 is induced, not only by its substrate heme, but also by various oxidative stresses $(1,2)$. It is thought to play an important protective role against oxidative tissue injuries because of its antiinflammatory and anti-apoptotic properties $(1,2)$. Hemorrhagic shock followed by resuscitation (HSR) induces oxidative stress that leads to multiple organ damage $(3,4)$, and the kidney is one of the target organs of HSR-mediated oxidative tissue injury (5). We previously reported that HO-1 mRNA was highly induced in the kidney after HSR in a rat model of HSR (6). However, the role of renal HO-1 induction following HSR remains elusive. In light of this, we examined the effect of HSR on functional HO-1 protein expression and its inhibition on tissue inflammation and injury in the kidney. The degree of tissue inflammation and injury was assessed by the mRNA levels of tumor necrosis factor (TNF)- $\alpha$ and inducible nitric oxide synthase (iNOS); expression of activated caspase-3, the key executioner of apoptosis (7); and the level of Bcl-2 mRNA, an anti-apoptotic gene (8). We here report that functional HO-1 protein is markedly induced in tubular epithelial cells of the kidney, which are the target cells of ischemic renal injury, after HSR. Apoptotic cell death was observed only in the cells in which HO-1 was not expressed. To note, pretreatment of rats with tin-mesoporphyrin (SnMP), a specific competitive inhibitor of $\mathrm{HO}$ activity (9), markedly inhibited HO-1 activity, aggravated apoptotic cell death and exacerbated tissue inflammation. Thus, HO-1 induction appears to be critical for protecting renal cells from oxidative stress caused by HSR.

\section{Materials and methods}

Animals. The studies reported herein conform to the Guidelines for the Care and Use of Laboratory Animals established by the Animal Use and Care Committee of the Okayama University Medical School. Male Sprague-Dawley rats weighing 380$420 \mathrm{~g}$ were purchased from Charles River Laboratories Japan, Inc. (Yokohama, Japan). They were housed in a temperature-controlled $\left(25^{\circ} \mathrm{C}\right)$ room with alternating 12 -h light/12-h dark cycles and were allowed free access to water and a chow diet until the start of the experiments.

Hemorrhagic shock protocol. Rats were anesthetized with intraperitoneal sodium pentobarbital $(50 \mathrm{mg} / \mathrm{kg})$ and 
subjected to sham or HSR, as described previously $(6,10,11)$. In brief, the left femoral artery and vein were dissected using aseptic techniques and cannulated with a heparinized polyethylene tube. Catheters were inserted into the left femoral artery and vein to measure blood pressure and induce hemorrhage, respectively. After measuring baseline blood pressure, hemorrhage was initiated by bleeding into a heparinized syringe $(10$ units $/ \mathrm{ml})$ for $15 \mathrm{~min}$ to achieve a mean arterial blood pressure of $30 \mathrm{mmHg}$. This blood pressure level $(30 \pm 5 \mathrm{mmHg})$ was maintained for $60 \mathrm{~min}$ by further blood withdrawal or by reinfusing the shed blood. At this point, animals were resuscitated for $15 \mathrm{~min}$ by re-administering all the shed blood, followed by injection of sterile saline as necessary until the blood pressure was restored to the baseline level. The sham group underwent all instrumentation procedures, but blood was not collected. The animals were allowed to breathe spontaneously throughout the experiment. To maintain body temperature within the physiological range, all procedures were performed over a heating pad with continuous monitoring of rectal body temperature. Electrocardiography was also monitored continuously.

Experimental design. HSR-treated rats were randomly assigned to the following two groups: pretreatment with SnMP before HSR (SnMP/HSR group) and pretreatment with vehicle before HSR (Vehicle/HSR group). SnMP $(0.5 \mu \mathrm{mol} / \mathrm{kg}$; Frontier Scientific, Logan, UT, USA) or vehicle was injected through the tail vein $1 \mathrm{~h}$ before the onset of HSR. SnMP was prepared immediately before use as described below. SnMP was dissolved in a small volume of $0.1 \mathrm{~N}$ $\mathrm{NaOH}$ solution, and the $\mathrm{pH}$ was adjusted to 7.6 with $0.01 \mathrm{M}$ sodium phosphate buffer (12). Sham animals were used as a control (Sham group). Under light anesthesia with ethyl ether, the animals were sacrificed by decapitation $3 \mathrm{~h}$ after HSR. The kidneys were excised and frozen immediately in liquid nitrogen and stored at $-80^{\circ} \mathrm{C}$ until needed for RNA preparation. To determine $\mathrm{HO}$ activity, the kidneys were first perfused in situ with physiological saline until the venous effluent became clear and were then removed for microsome preparation.

cDNA probes. Template cDNA for HO-1, TNF- $\alpha$, iNOS and Bcl-2 were prepared as described previously $(10,13)$. All probes used for Northern blot analysis were $\left[\alpha-{ }^{32} \mathrm{P}\right] \mathrm{dCTP}-$ labeled cDNA probes prepared using a random primer DNA labeling system (both from Amersham Pharmacia Biotech, Piscataway, NJ, USA) according to the manufacturer's instructions.

RNA isolation and Northern blot analysis. Total RNA was isolated from rat tissues using Tri-Reagent ${ }^{\mathrm{TM}}$ (Sigma Chemical, St. Louis, MO, USA) according to the manufacturer's protocol. Northern blotting was performed as described previously $(10,11)$. Total RNA $(20 \mu \mathrm{g})$ was subjected to electrophoresis on $1.2 \%(\mathrm{w} / \mathrm{v})$ agarose gels containing $6.5 \%(\mathrm{v} / \mathrm{v})$ formaldehyde. After blotting on a sheet of Bio-Rad Zeta-Probe membrane (Bio-Rad Laboratories, Richmond, CA, USA), RNA samples were hybridized with the $\left[\alpha^{-}{ }^{32} \mathrm{P}\right] \mathrm{dCTP}-$ labeled cDNA probes, followed by washing under stringent conditions. The membrane was exposed to a sheet of Fuji Medical radiograph film with an intensifying screen at $-70^{\circ} \mathrm{C}$, and autoradiographs and $18 \mathrm{~S}$ ribosomal RNA were quantified using an image scanner (GelPrint ${ }^{\mathrm{TM}}$ 2000i; Genomic Solutions, Ann Arbor, MI, USA) and computerized image analysis software (Basic Quantifier ${ }^{\mathrm{TM}}$ version 3.0, Genomic Solutions). The relative amounts of radiolabeled cDNA that hybridized to the blots were normalized to $18 \mathrm{~S}$ ribosomal RNA levels to correct for loading errors.

Immunohistochemistry. Immunohistochemical analysis was performed using the indirect immunofluorescence method. Renal tissue was fixed in $10 \%$ neutral-buffered formalin, embedded in paraffin, and sectioned at a thickness of 4-6 $\mu \mathrm{m}$. Following antigen retrieval in citrate buffer $(0.01 \mathrm{M}, \mathrm{pH} 6.0)$ with heat treatment by autoclaving, nonspecific binding sites were blocked with 5\% normal donkey serum for $30 \mathrm{~min}$. Slides were then incubated at $4^{\circ} \mathrm{C}$ overnight with a monoclonal mouse HO-1 antibody (StressGen Biotechnologies, Victoria, BC, Canada) and a polyclonal rabbit cleaved caspase-3 antibody (Cell Signaling Technology, Beverly, MA, USA) at a dilution of 1:100 in $1 \mathrm{X}$ phosphate-buffered saline (PBS) containing 0.3\% Triton X-100. For fluorescent visualization of the bound primary antibody, the slides were further incubated with fluorescein isothiocyanate (FITC)conjugated donkey anti-mouse $\mathrm{IgG}$ (Chemicon ${ }^{\mathrm{TM}}$ International, Temecula, CA, USA) with a green fluorescent label and Cy3conjugated donkey anti-rabbit IgG (Chemicon International) with a red fluorescent label for $90 \mathrm{~min}$. Normal mouse and rabbit serum were used as the control for nonspecific staining. Images were taken with a Zeiss confocal laser scanning microscope model LSM510 (Zeiss, Jena, Germany).

$\mathrm{HO}$ activity. Renal HO activity was measured as described previously (12). Tissue was homogenized in three volumes of $0.05 \mathrm{M}$ Tris- $\mathrm{HCl}$ (pH 7.8) containing $0.25 \mathrm{M}$ sucrose, $20 \%$ (w/v) glycerol, 3 units/ml heparin, and a protease inhibitor (Complete, Roche Diagnostics GmbH, Mannheim, Germany) and centrifuged at $10,000 \mathrm{x}$ g for $15 \mathrm{~min}$ at $4^{\circ} \mathrm{C}$. The supernatant was collected and centrifuged at $105,000 \mathrm{x}$ g for $60 \mathrm{~min}$ at $4^{\circ} \mathrm{C}$. After centrifugation, the microsomal pellet was collected and resuspended in $20 \mathrm{mM}$ Tris- $\mathrm{HCl}(\mathrm{pH} 7.4)$ containing $1.15 \% \mathrm{KCl}$ and a protease inhibitor and used to measure $\mathrm{HO}$ activity spectrophotometrically, as described previously. The cytosolic fraction prepared from the liver of adult untreated rats served as a source of biliverdin reductase in the $\mathrm{HO}$ assay. $\mathrm{HO}$ activity was expressed as picomoles of bilirubin formed per milligram of protein per $60 \mathrm{~min}$.

Statistical analysis. The results are expressed as means \pm standard deviations. Statistical analysis was performed using an analysis of variance. A probability level of $\mathrm{p}<0.05$ was considered statistically significant.

\section{Results}

HO-1 protein expression. We previously reported that the HO-1 mRNA level increased markedly following HSR in the rat kidney (6). Thus, we examined the effect of HSR on HO- 1 protein expression in the kidney by fluorescent 


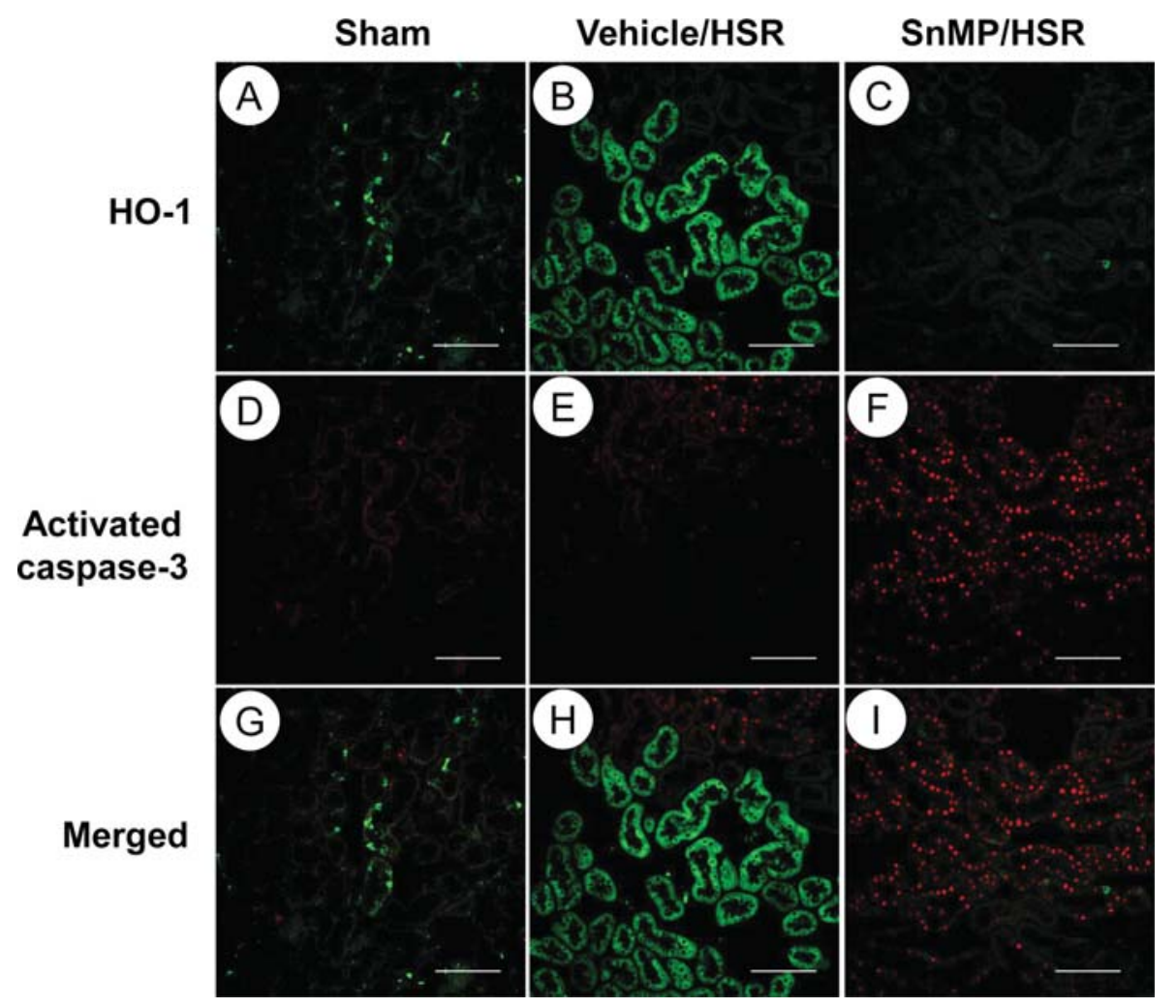

Figure 1. Effect of hemorrhagic shock followed by resuscitation (HSR) on heme oxygenase-1 (HO-1) and activated caspase-3 expression in the kidney and their modulation by tin-mesoporphyrin (SnMP) administration. Vehicle or SnMP $(0.5 \mu \mathrm{mol} / \mathrm{kg})$ was intravenously administered to rats $1 \mathrm{~h}$ before HSR. Sections from kidneys $12 \mathrm{~h}$ after HSR were subjected to fluorescent immunohistochemical analysis of HO-1 (green signals) and activated caspase-3 (red signals), as described in Materials and methods. Top row: HO-1-positive cells in Sham (A), Vehicle/HSR (B) and SnMP/HSR (C); Middle row: activated caspase-3-positive cells in Sham (D), Vehicle/HSR (E) and SnMP/HSR (F); Bottom row: merged images of HO-1 and activated caspase-3 in Sham (G), Vehicle/HSR (H) and SnMP/HSR (I). Sham, sham-operated control animals; Vehicle/HSR, vehicle-treated HSR animals; SnMP/HSR, SnMP-treated HSR animals. Bars, $100 \mu \mathrm{m}$. Original magnification, x200.

immunohistochemical analysis and by measuring $\mathrm{HO}$ activity $12 \mathrm{~h}$ after HSR. HO-1-positive cells were negligibly detectable in the sham-operated control animals (Fig. 1A and G). However, strong positive signals (green color) for the HO-1 protein were predominantly observed in the tubular epithelial cells of the kidney in the HSR animals (Fig. 1B and H). Consistent with HO-1 protein expression, HSR increased HO activity in the kidney of the HSR animals by $\sim 3$-fold compared to that of the sham-operated control animals (Fig. 2). In contrast, administering SnMP, a specific competitive inhibitor of HO, to the HSR animals quenched HO-1 signals in the tubular epithelial cells (Fig. 1C and I) and decreased HO activity almost to the same level as that in the sham-operated control animals (Fig. 2). These results revealed that HSR treatment markedly increased functional $\mathrm{HO}-1$ protein in the tubular epithelial cells of the kidney and that SnMP administration completely inhibited the HSR-mediated increase in HO activity.

TNF- $\alpha$ and iNOS gene expression. Since HO-1 has an antiinflammatory property, we examined the effect of HSR on the gene expression of pro-inflammatory mediators, such as TNF- $\alpha$ and iNOS, in the kidney and its modulation by SnMP. While TNF- $\alpha$ and iNOS mRNA was barely detectable in the kidney of the sham-operated animals, these mRNA levels only slightly increased after HSR (Fig. 3). These data were consistent with our previous observation (6) and suggested

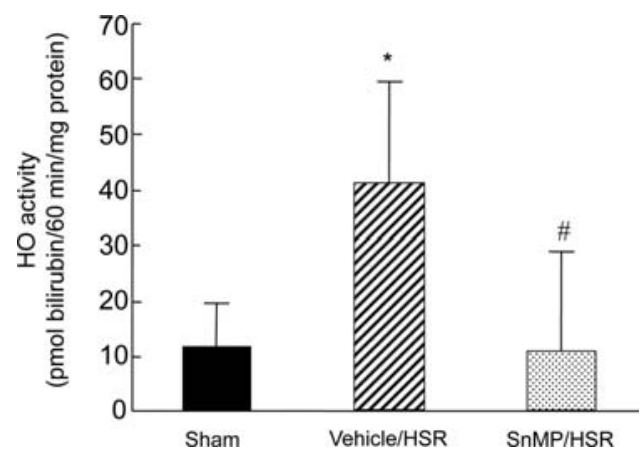

Figure 2. Effect of HSR on HO activity in the kidney and its modulation by SnMP administration. Vehicle or SnMP $(0.5 \mu \mathrm{mol} / \mathrm{kg})$ was intravenously administered to rats $1 \mathrm{~h}$ before HSR. The kidney was removed $12 \mathrm{~h}$ after HSR, and HO activity was measured as described in Materials and methods. Sham, sham-operated control animals; Vehicle/HSR, vehicle-treated HSR animals; SnMP/HSR, SnMP-treated HSR animals. Data are presented as means $\pm \mathrm{SD}(\mathrm{n}=5) .{ }^{*} \mathrm{p}<0.05$ vs. Sham; ${ }^{*} \mathrm{p}<0.05$ vs. Vehicle/HSR.

that HO-1 may suppress HSR-induced activation of these pro-inflammatory genes. In support of our hypothesis, when animals were treated with SnMP before inducing hemorrhagic shock, the levels of TNF- $\alpha$ and iNOS mRNA increased markedly compared to those of the vehicle-treated HSR animals (Fig. 3). The average levels of TNF- $\alpha$ and iNOS mRNA in the SnMP-pretreated animals were $~ 5$ - and 4-fold 

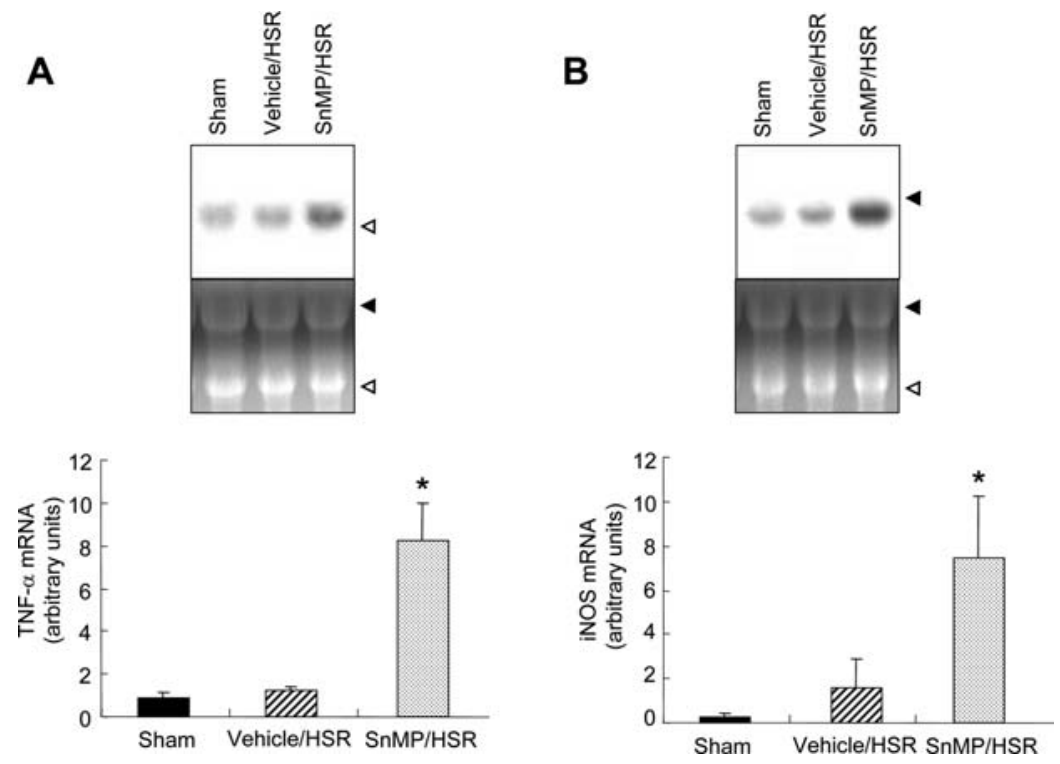

Figure 3. Effect of HSR on tumor necrosis factor (TNF)- $\alpha$ and inducible nitric oxide synthase (iNOS) gene expression in the kidney and their modulation by SnMP administration. Vehicle or SnMP $(0.5 \mu \mathrm{mol} / \mathrm{kg})$ was intravenously administered to rats $1 \mathrm{~h}$ before HSR. Total RNA was extracted from the kidney $3 \mathrm{~h}$ after HSR, and TNF- $\alpha$ (A) and iNOS (B) gene expression was analyzed by Northern blot analysis. Top, autoradiographic signals of the RNA blot hybridized with $\left[\alpha-{ }^{32} \mathrm{P}\right] \mathrm{dCTP}-\mathrm{labeled}$ TNF- $\alpha$ and iNOS cDNA with ethidium bromide-stained gels. Open and closed arrowheads next to the autoradiogram indicate the positions of $18 \mathrm{~S}$ and $28 \mathrm{~S}$ ribosomal RNA corresponding to the ethidium bromide-stained gels, respectively. Sham, sham-operated control animals; Vehicle/HSR, vehicle-treated HSR animals; and SnMP/HSR, SnMP-treated HSR animals. Bottom, levels of TNF- $\alpha$ and iNOS mRNA are expressed as arbitrary units. Data are presented as means $\pm \mathrm{SD}(\mathrm{n}=5) .{ }^{*} \mathrm{p}<0.05$ vs. Sham or Vehicle/HSR.
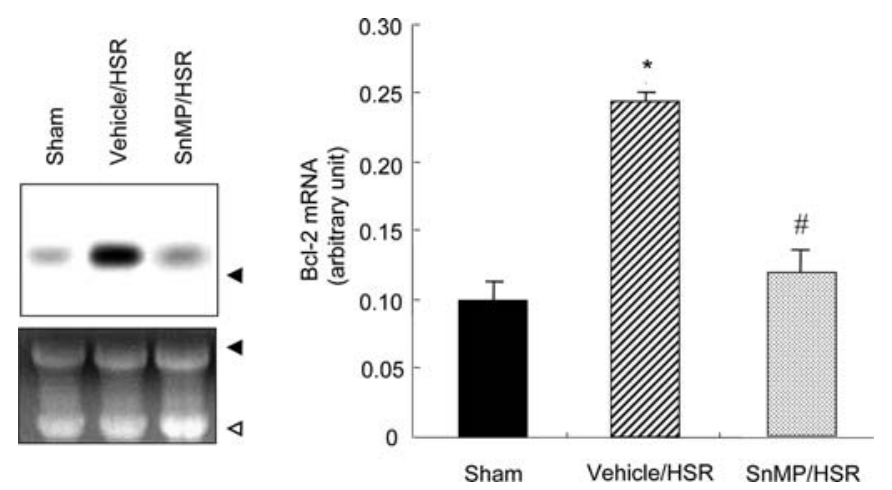

Figure 4. Effect of HSR on Bcl-2 gene expression in the kidney and its modulation by SnMP administration. Vehicle or SnMP $(0.5 \mu \mathrm{mol} / \mathrm{kg})$ was intravenously administered to rats $1 \mathrm{~h}$ before HSR. Total RNA was extracted from the kidney $3 \mathrm{~h}$ after HSR, and Bcl-2 gene expression was analyzed by Northern blot analysis. Left, autoradiographic signals of the RNA blot hybridized with $\left[\alpha^{-}{ }^{32} \mathrm{P}\right] \mathrm{dCTP}-$ labeled Bcl-2 cDNA with the ethidium bromide-stained gels. Open and closed arrowheads next to the autoradiogram indicate the positions of $18 \mathrm{~S}$ and $28 \mathrm{~S}$ ribosomal RNA corresponding to the ethidium bromidestained gels, respectively. Sham, Sham-operated control animals; Vehicle/HSR, Vehicle-treated HSR animals; SnMP/HSR, SnMP-treated HSR animals. Right, Bcl-2 mRNA levels are expressed as arbitrary units. Data are presented as means $\pm \mathrm{SD}(\mathrm{n}=5)$. ${ }^{\mathrm{p}}<<0.05$ vs. Sham; ${ }^{*} \mathrm{p}<0.05$ vs. Vehicle/HSR.

higher than those of the vehicle-treated HSR animals, respectively. These results indicate that tissue inflammation was markedly enhanced by HO-1 inhibition.

Activated caspase-3 and Bcl-2 expression. Since tissue inflammation promotes oxidative stress which leads to apoptotic cell death, and HO-1 has anti-apoptotic property (14), we examined the effect of HSR on apoptotic cell death and its modulation by SnMP. Apoptotic cell death was specifically assessed using fluorescent immunohistochemical staining of activated caspase-3, the key executioner of apoptosis, $12 \mathrm{~h}$ after HSR (8) and by Northern blot analysis of Bcl-2 mRNA, the key anti-apoptotic gene (7), $3 \mathrm{~h}$ after
HSR. While activated caspase-3 signals were hardly detectable in the kidneys of sham-operated animals (Fig. 1D and G), the kidney sections from the vehicle-treated HSR animals only marginally expressed positive signals (Fig. 1E). Of note, these signals were merely observed in the renal tubular epithelial cells where HO-1 was not expressed (Fig. 1H). When HSR animals were pretreated with SnMP, the positive signals of activated caspase- 3 were obviously increased and distributed homogeneously in the kidney (Fig. $1 \mathrm{~F}$ and I). Bcl-2 mRNA was significantly expressed in the sham-operated control animals; however, its level was further increased in the vehicle-treated HSR animals (Fig. 4). In contrast, SnMP pretreatment decreased Bcl-2 mRNA expression, which 
reached a level similar to that in the sham animals (Fig. 4). Thus, these findings suggest that apoptosis increased significantly by inhibiting $\mathrm{HO}$ activity by SnMP treatment.

\section{Discussion}

We demonstrated that HSR induced functional HO-1 protein in the tubular epithelial cells of the kidney, while there was only a marginal increase in gene expression of proinflammatory mediators such as TNF- $\alpha$ and iNOS and a significant increase in the gene expression of Bcl-2, an antiapoptotic gene, in the kidney after HSR. Although activated caspase-3 was slightly expressed in the kidney after HSR, its expression was only observed in the renal cells where HO-1 was not expressed. Of note, our findings also demonstrated that inhibition of HO activity by SnMP markedly aggravated tissue inflammation and apoptotic cell death induced by HSR. These findings suggest that the maintenance of induced $\mathrm{HO}$ activity is essential for protecting the kidney from HSRinduced oxidative tissue injury.

HSR incites an inflammatory response characterized by the upregulation of pro-inflammatory mediators, which are responsible for highly complex cascading events leading to oxygen radical generation (3). Reactive oxygen species induce apoptotic cell death, ultimately resulting in tissue injury $(15,16)$. Conversely, oxidative stresses provoke cellular protective responses, principally involving transcriptional activation of genes encoding proteins that participate in the defense against oxidative tissue injuries (17). HO- 1 is induced by oxidative stress and is thought to protect against oxidative tissue injuries $(1,2)$. Recent studies, including those from our laboratory, strongly indicate that the protective effect of HO-1 against oxidative stress can be attributed to its anti-inflammatory and anti-apoptotic properties $(18,19)$. In support of this notion, as shown in Fig. 1, following HSR, functional HO-1 protein was highly induced in the tubular epithelial cells of the kidney, which are the target cells of HSR-induced renal injury. In contrast to enhanced HO-1 protein expression, mRNA levels of the pro-inflammatory mediators TNF- $\alpha$ and iNOS showed only marginal increases after HSR (Fig. 3). Moreover, although positive signals of activated caspase- 3 were slightly detectable after HSR, they were only observed in the tubular epithelial cells where HO-1 was not expressed (Fig. 1). The anti-inflammatory and antiapoptotic properties of renal HO-1 induced by HSR were further confirmed by the fact that inhibiting HO-1 by SnMP treatment resulted in a marked elevation of mRNA levels of TNF- $\alpha$ and iNOS (Fig. 3), a further increase in activated caspse-3-positive cells (Fig. 1), and a reduction in Bcl-2 mRNA levels, which were increased by HSR (Fig. 4). In particular, the increase in iNOS mRNA level by inhibiting $\mathrm{HO}$ activity is of great importance as numerous in vivo and in vitro investi-gations have demonstrated that inhibiting the expression of iNOS activity or the absence of iNOS itself can ameliorate or prevent renal ischemia/reperfusion injury (20).

The precise mechanism by which increased HO-1 activity produces anti-inflammatory and anti-apoptotic effects is yet to be demonstrated definitively. HO-1 oxidatively cleaves heme and yields three metabolites: iron, biliverdin and carbon monoxide. In doing so, HO-1 reduces cellular concentrations of free heme, a pro-oxidant and tissue inflammation activator $(21,22)$. In good agreement with this notion, we previously demonstrated that inducing renal HO- 1 in a rat model of ischemic acute renal failure degrades an excess amount of free heme, presumably derived from degenerated cytochrome P450 by ischemia to protect tubular epithelial cells from further damage (23). In addition to heme removal, HO-1 metabolites also have significant biological properties. Although excess free iron is cytotoxic because it catalyzes the Fenton reaction to generate free radicals (24), iron produced by HO-1 is directly sequestered by ferritin, leading to additional anti-oxidant (25) and anti-apoptotic effects (26). Biliverdin is rapidly converted to bilirubin by bilirubin reductase, and both biliverdin and bilirubin function as potent endogenous anti-oxidants (27). Bilirubin itself is oxidized to biliverdin and then recycled back to bilirubin by biliverdin reductase, suggesting further amplification of their antioxidant effects (28). In fact, bilirubin treatment has recently been shown to improve renal vascular resistance, urine output, glomerular filtration rate, tubular function, and mitochondrial integrity after renal ischemia/reperfusion (29). CO also exerts anti-inflammatory and anti-apoptotic activities that are thought to be mediated, at least in part, by activating the p38 mitogen-activated protein kinase signaling pathway $(14,30)$. In this regard, it has been reported that in a rat model of transplant-induced renal I/R injury, administration of $250 \mathrm{ppm}$ $\mathrm{CO}$ gas to rats resulted in a significant improvement in graft renal function associated with significant reduction in tubular epithelial cell apoptosis and decrease in pro-inflammatory mediators (31). Accordingly, HO-1 reactions in the kidney may provide a fundamental protective milieu for tubular epithelial cells to cope with HSR-induced oxidative tissue injury by favoring the removal of the pro-oxidant heme and increasing the amount of anti-oxidative, anti-inflammatory, and anti-apoptotic heme metabolites. While it remains unclear as to what extent each mechanism may contribute to this process, these findings may all be important in the host cellular defense against oxidative tissue injuries.

\section{Acknowledgements}

The authors thank Dr Reiko Akagi, Professor, Yasuda University, Hiroshima, Japan, for providing cDNAs for TNF- $\alpha$, iNOS and Bcl-2. This study was supported, in part, by a Grant-in-Aid for Scientific Research from the Ministry of Education, Culture, Sports, Science and Technology of Japan.

\section{References}

1. Takahashi T, Shimizu H, Morimatsu H, Maeshima K, Inoue K, Akagi R, Matsumi M, Katayama $\mathrm{H}$ and Morita K: Heme oxygenase- 1 is an essential cytoprotective component in oxidative tissue injury induced by hemorrhagic shock. J Clin Biochem Nutr 44: 28-40, 2009.

2. Takahashi T, Shimizu H, Morimatsu H, Inoue K, Akagi R, Morita $\mathrm{K}$ and Sassa S: Heme oxygenase-1: a fundamental guardian against oxidative tissue injuries in acute inflammation. Mini Rev Med Chem 7: 745-753, 2007.

3. Jarrar D, Chaudry IH and Wang P: Organ dysfunction following hemorrhage and sepsis: Mechanisms and therapeutic approaches (Review). Int J Mol Med 4: 575-583, 1999.

4. Rushing GD and Britt LD: Reperfusion injury after hemorrhage: a collective review. Ann Surg 247: 929-937, 2008. 
5. Takahashi T, Morita K, Akagi R and Sassa S: Protective role of heme oxygenase-1 in renal ischemia. Antioxid Redox Signal 6: 867-877, 2004.

6. Maeshima K, Takahashi T, Uehara K, Shimizu H, Omori E, Yokoyama M, Tani T, Akagi R and Morita K: Prevention of hemorrhagic shock-induced lung injury by heme arginate treatment in rats. Biochem Pharmacol 69: 1667-1680, 2005.

7. Cohen GM: Caspases: the executioners of apoptosis. Biochem J 326: 1-16, 1997.

8. Brown R: The bcl-2 family of proteins. Br Med Bull 53: 466-477, 1997.

9. Drummond GS, Galbraith RA, Sardana MK and Kappas A: Reduction of the C2 and C4 vinyl groups of Sn-protoporphyrin to form Sn-mesoporphyrin markedly enhances the ability of the metalloporphyrin to inhibit in vivo heme catabolism. Arch Biochem Biophys 255: 64-74, 1987.

10. Toda Y, Takahashi T, Maeshima K, Shimizu H, Inoue K, Morimatsu H, Omori E, Takeuchi M, Akagi R and Morita K: A neutrophil elastase inhibitor, sivelestat, ameliorates lung injury after hemorrhagic shock in rats. Int J Mol Med 19: 237-243, 2007.

11. Nishie H, Takahashi T, Inoue K, Shimizu H, Morimatsu H, Toda Y, Omori E, Akagi R, Katayama H and Morita T: Sitespecific induction of intestinal hypoxia-inducible factor-lalpha after hemorrhagic shock. Mol Med Rep 2: 149-152, 2009.

12. Kawakami T, Takahashi T, Shimizu H, Nakahira K, Takeuchi M, Katayama H, Yokoyama M, Morita K, Akagi R and Sassa S Highly liver-specific heme oxygenase- 1 induction by interleukin-11 prevents carbon tetrachloride-induced hepatotoxicity Int J Mol Med 18: 537-546, 2006.

13. Uehara K, Takahashi T, Fujii H, Shimizu H, Omori E, Matsumi M, Yokoyama M, Morita K, Akagi R and Sassa S: The lower intestinal tract-specific induction of heme oxygenase-1 by glutamine protects against endotoxemic intestinal injury. Crit Care Med 33: 381-390, 2005.

14. Brouard S, Otterbein LE, Anrather J, Tobiasch E, Bach FH, Choi AM and Soares MP: Carbon monoxide generated by heme oxygenase 1 suppresses endothelial cell apoptosis. J Exp Med 192: 1015-1026, 2000

15. Fink MP: Reactive oxygen species as mediators of organ dysfunction caused by sepsis, acute respiratory distress syndrome or hemorrhagic shock: potential benefits of resuscitation with Ringer's ethyl pyruvate solution. Curr Opin Clin Nutr Metab Care 5: 167-174, 2002.

16. Tharakan B, Hunter FA, Smythe WR and Childs EW: Alphalipoic acid attenuates hemorrhagic shock-induced apoptotic signaling and vascular hyperpermeability. Shock 30: 571-577, 2008.

17. Rahman I, Biswas SK and Kode A: Oxidant and antioxidant balance in the airways and airway diseases. Eur J Pharmacol 533: 222-239, 2006.

18. Inoue K, Takahashi T, Uehara K, Shimuzu H, Ido K, Morimatsu H, Omori E, Katayama H, Akagi $\mathrm{R}$ and Morita K: Protective role of heme oxygenase 1 in the intestinal tissue injury in hemorrhagic shock in rats. Shock 29: 252-261, 2008.
19. Umeda K, Takahashi T, Inoue K, Shimizu H, Maeda S, Morimatsu H, Omori E, Akagi R, Katayama H and Morita K: Prevention of hemorrhagic shock-induced intestinal tissue injury by glutamine via heme oxygenase- 1 induction. Shock 31 : 40-49, 2009.

20. Goligorsky MS, Brodsky SV and Noiri E: Nitric oxide in acute renal failure: NOS versus NOS. Kidney Int 61: 855-861, 2002.

21. Graca-Souza AV, Arruda MA, de Freitas MS, Barja-Fidalgo C and Oliveira PL: Neutrophil activation by heme: implications for inflammatory processes. Blood 99: 4160-4165, 2002.

22. Jeney V, Balla J, Yachie A, Varga Z, Vercellotti GM, Eaton JW and Balla G: Pro-oxidant and cytotoxic effects of circulating heme. Blood 100: 879-887, 2002.

23. Shimizu H, Takahashi T, Suzuki T, Yamasaki A, Fujiwara T, Odaka Y, Hirakawa M, Fujita H and Akagi R: Protective effect of heme oxygenase induction in ischemic acute renal failure. Crit Care Med 28: 809-817, 2000.

24. McCord JM: Oxygen-derived free radicals. New Horiz 1: 70-76, 1993.

25. Balla G, Jacob HS, Balla J, Rosenberg M, Nath K, Apple F, Eaton JW and Vercellotti GM: Ferritin: a cytoprotective antioxidant strategem of endothelium. J Biol Chem 267: 18148-18153, 1992.

26. Choi BM, Pae HO, Jeong YR, Oh GS, Jun CD, Kim BR, Kim YM and Chung HT: Overexpression of heme oxygenase (H0)-1 renders Jurkat $\mathrm{T}$ cells resistant to fas-mediated apoptosis: involvement of iron released by HO-1. Free Radic Biol Med 36: 858-871, 2004

27. Stacker R, Yamamoto Y, McDonagh AF, Glazer AN and Ames BN: Bilirubin is an antioxidant of possible physiological importance. Science 235: 1043-1046, 1987.

28. Baranano DE, Rao M, Ferris CD and Snyder SH: Biliverdin reductase: a major physiologic cytoprotectant. Proc Natl Acad Sci USA 99: 16093-16098, 2002.

29. Adin CA, Croker BP and Agarwal A: Protective effects of exogenous bilirubin on ischemia-reperfusion injury in the isolated, perfused rat kidney. Am J Physiol Renal Physiol 288: F778-F784, 2005.

30. Otterbein LE, Bach FH, Alam J, Soares M, Tao Lu H, Wysk M, Davis RJ, Flavell RA and Choi AM: Carbon monoxide has antiinflammatory effects involving the mitogen-activated protein kinase pathway. Nat Med 6: 422-428, 2000.

31. Neto JS, Nakao A, Kimizuka K, Romanosky AJ, Stolz DB, Uchiyama T, Nalesnik MA, Otterbein LE and Murase N: Protection of transplant-induced renal ischemia-reperfusion injury with carbon monoxide. Am J Physiol Renal Physiol 287: F979-F989, 2004. 